\title{
A study of peroxidase levels in human cervical mucus as an index of ovulation
}

\author{
J. S. Shindler*, Kathleen Haworth, Audrey Axon, W. G. Bardsley, \\ V. R. Tindall and I. Laing $\dagger$ \\ Department of Obstetrics and Gynaecology, The University of Manchester, \\ Saint Mary's Hospital, and †Department of Clinical Biochemistry, \\ Manchester Royal Infirmary, Manchester, U.K.
}

\begin{abstract}
Summary. Fourteen healthy women were screened for the following parameters throughout one complete menstrual cycle: levels of urinary oestrogens and pregnanediol; levels of plasma and urinary gonadotrophins; and $\mathrm{pH}$, protein content and levels of peroxidase in the cervical mucus. It was found that concentrations of peroxidase in the cervical mucus were not a reliable index of ovulation.
\end{abstract}

\section{Introduction}

The various biochemical and radioimmunoassay methods used for confirmation of ovulation are still relatively time-consuming, expensive and require skilled technical help. Any possible simple and reliable method therefore requires to be studied in detail. In 1958, Birnberg, Kurzrok \& Laufer described a colour test for ovulation in women based on a glucose oxidase assay which develops a blue colour which seems to be most intense at ovulation. In practice this test has the disadvantage of introducing a potentially carcinogenic dye deep into the cervical canal. In cattle the level of peroxidase in the cervical mucus can be used for the detection of ovulation. This test in cattle is carried out by means of a suitably impregnated finger-stall which can be inserted into the cervix. The intensity of the resulting colour change is approximately proportional to the amount of enzyme present. The amount of enzyme drops significantly at oestrus, i.e. 16-18 h before ovulation (Linford, 1974).

Peroxidase has also been found to be a normal constituent of human cervical mucus and some preliminary studies on the correlation of peroxidase activity with different phases of the menstrual cycle have been described (Blain, Heald, Mack \& Shaw, 1975). These authors found no obvious correlations but their results were obtained from single measurements in different women and the time of ovulation had not been determined.

In the present study we measured concentrations of serum and urinary gonadotrophins and urinary steroids to permit assignment of the most probable time of ovulation, and levels of peroxidase in samples of cervical mucus.

\section{Materials and Methods}

\section{Collection of mucus and measurement of $\mathrm{pH}$}

Samples of cervical mucus were collected, by means of a sterile pipette, on a day-to-day basis throughout one complete menstrual cycle from 14 healthy volunteers not taking oral contraceptives. The samples were applied to a universal $\mathrm{pH}$ indicator paper (accurate to $\pm 0.1 \mathrm{pH}$ unit) before being flushed into a container with $1 \mathrm{ml} 0 \cdot 1 \mathrm{M}$-sodium acetate buffer, adjusted to $\mathrm{pH} 4 \cdot 4$ with glacial acetic acid.

The quantity and viscosity of the mucus varied considerably during the cycle. Each sample was ground in an hand homogenizer and the resulting suspension was centrifuged at $7000 \mathrm{~g}$ for $10 \mathrm{~min}$

* Present address: Department of Biochemistry, The University of Cambridge, Tennis Court Road, Cambridge, U.K. 
at $20^{\circ} \mathrm{C}$ to remove debris. Protein estimations and peroxidase assays were performed on $0.05 \mathrm{ml}$ aliquots of the supernatants. For protein estimation the aliquot was diluted to $1 \mathrm{ml}$ with $0.1 \mathrm{M}$ acetate buffer, $\mathrm{pH} 4 \cdot 4$, and treated with Folin-Ciocalteau reagent as described by Hartree (1972). The resulting complex was measured spectrophotometrically at $650 \mathrm{~nm}$ and the protein content of the samples was determined by comparison with a standard calibration curve constructed by analogous measurements of solutions of known concentration of bovine serum albumin.

\section{Peroxidase assay}

The chromogen of choice was 2,2'-azino-di(3-benzthiazoline-6-sulphonic acid) (ABTS, Boehringer, Mannheim). This substance is oxidized to a radical cation with an absorption at $412 \mathrm{~nm}$ under the assay conditions used of $3.24 \times 10^{4} \mathrm{M}^{-1} \mathrm{~cm}^{-1}$. The chemistry of this process has been described (Childs \& Bardsley, 1975) and the peroxidase of human cervical mucus has been purified and characterized by steady-state kinetic studies (Shindler, Childs \& Bardsley, 1976). In each assay, 0.05 ml aliquots of the mucous samples were added to the acetate buffer, pH 4.4 with $1 \mathrm{mM}$-ABTS and $0 \cdot 1$ mM-hydrogen peroxide in a final cuvette volume of $1 \mathrm{ml}$. Absorbance changes were measured at $20^{\circ} \mathrm{C}$ with a CARY 118C UV-VIS spectrophotometer and rates were linear for at least $2 \mathrm{~min}$. Several substrates of peroxidase were compared with ABTS for the sensitivity of the spectrophotometric assay. At a concentration of $0 \cdot 1 \mathrm{mM}-\mathrm{H}_{2} \mathrm{O}_{2}$ and $5 \mathrm{~mm}$-substrate, the relative rates of oxidation were: ABTS, 100; $o$-dianisidine, 21 ; pyrogallol, 5; guaiacol, 1; and 4-aminophenazone, 0.75.

\section{Gonadotrophin measurements}

LH and FSH were measured by double-antibody radioimmunoassays similar to that described by Midgley (1966). Serum assays were performed with materials supplied by the National Pituitary Agency, Bethesda, Maryland. The LH (batch LER-960) and FSH (batch LER 1366) were radioiodinated for $15 \mathrm{sec}$ by the method of Greenwood, Hunter \& Glover (1963). The pituitary preparation LER 907 was used as standard in the serum assays and results were expressed as $\mu \mathrm{g}$ equivalents LER 907/1. Assays on unprocessed urine were similarly performed except that a commercial antiserum (RD 02: Burroughs Wellcome, Kent) was used in the LH assay. Urine results were expressed as i.u. second IRP-HMG/l.

The antisera used exhibited minimal mutual cross-reactivity when tested against highly purified pituitary gonadotrophic hormones (anti-FSH was tested against LER 960 and anti-LH against LER 1366), except for the antiserum RD 02 which may have overestimated $\mathrm{LH}$ in the presence of high FSH levels. Gonadotrophin measurements from the same patient were made in single assays in which the coefficient of variation for $\mathrm{LH}$ and FSH was $8 \%$ or less. The sensitivity of the LH assay was $10 \mu \mathrm{g} / \mathrm{ml}$ serum and 15 i.u./l urine. Several urine samples had LH levels below this limit.

\section{Urinary oestrogen and pregnanediol measurements}

Urinary oestrogens were measured by the method of Brown, MacLeod, Macnaughtan, Smith \& Smyth (1968), modified by the omission of a spectrofluorometric correction procedure. This results in an overestimation of the oestrogen content by up to $20 \mathrm{nmol} / \mathrm{l}$. The between-batch coefficient of variation of the oestrogen assay was $12 \%$.

Urinary pregnanediol was estimated by gas-liquid chromatography on $3 \%$ carbowax 20 MTPA on 100-120 mesh Chromosorb W AWMCS. The analyses were carried out on urine extracts after acid hydrolysis, toluene extraction and trimethylsilylether formation. The between batch coefficient of variation was $19 \%$ and the sensitivity of the method was $0.6 \mu \mathrm{mol}$ pregnanediol $/ 1$.

\section{Results}

Table 1 summarizes the findings for 13 of the volunteers. Although there is considerable variation in the duration of the menstrual cycles, ovulation was considered to have been confirmed in each woman. 

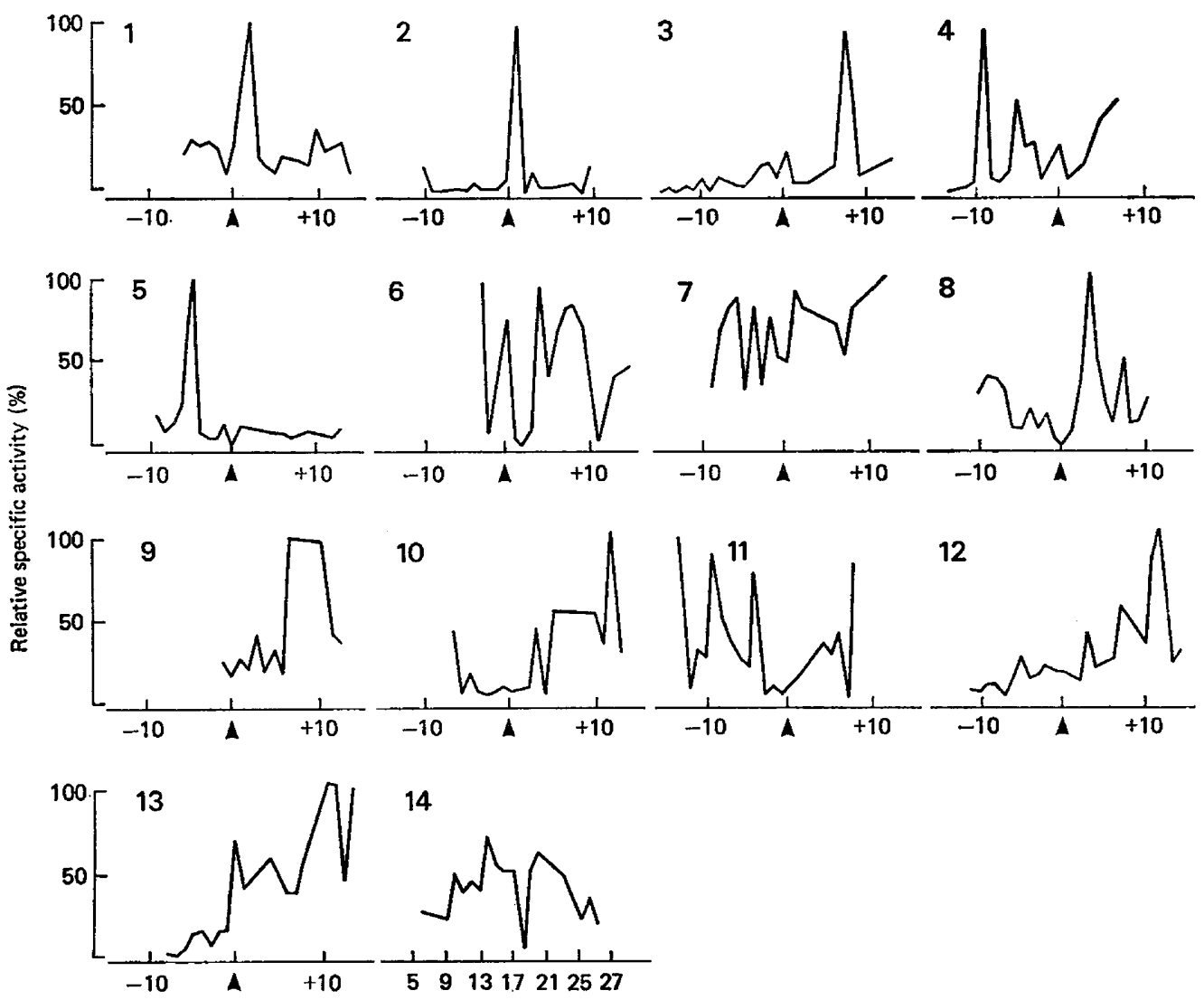

Days

Text-fig. 1. The activity (expressed as a percentage of the maximum specific activity in each cycle) of peroxidase in samples of human cervical mucus throughout the menstrual cycle of 14 volunteers (the number in each panel identifies the volunteer: see Table 1). The day of ovulation is indicated by the arrow and the day of ovulation, judged from hormonal criteria (see Table 1) and particularly the serum LH peak, is Day 0 . The cycle for Woman 14 was adjudged non-ovulatory and the days are numbered from the first day of menstruation.

The 14th volunteer was adjudged by these hormonal criteria not to have ovulated and this, although not an initial intention, did allow study of the peroxidase levels in cervical mucus in a non-ovulatory cycle.

As shown in Text-fig. 1, there was no characteristic peak or trough of peroxidase activity at the time of ovulation except possibly for Women 1 and 2. In some instances, one or two peaks occurred before and/or after ovulation. In the anovulatory cycle a wide fluctuation of activity was seen. There was no constant pattern of peroxidase activity in the women studied but in most of the cycles there was a slightly higher peroxidase activity after ovulation, perhaps related to the fact that it is easier to obtain samples during this phase of the menstrual cycle. The amount of soluble protein in each sample of mucus (data not shown) corresponded closely to the peroxidase pattern in that woman.

\section{Discussion}

The bactericidal properties of cervical mucus have been reported to be lower at ovulation than at any other time (Enhorning, Huldt \& Melen, 1970). Hydrogen peroxide, which is rapidly destroyed by 
Table 1. Hormonal measurements in 13 women to determine the time of ovulation

\begin{tabular}{|c|c|c|c|c|c|c|c|c|c|c|c|c|c|}
\hline & \multicolumn{13}{|c|}{ Women } \\
\hline & 1 & 2 & 3 & 4 & 5 & 6 & 7 & 8 & 9 & 10 & 11 & 12 & 13 \\
\hline Cycle length (days) & 28 & 27 & 37 & 29 & 34 & 26 & 29 & 33 & 26 & 32 & 37 & 31 & 32 \\
\hline $\begin{array}{l}\text { Mid-cycle urinary } \\
\text { oestrogen peak }\end{array}$ & & & & & & & & & & & & & 430 \\
\hline $\begin{array}{l}(\mathrm{nmol} / 24 \mathrm{~h}) \\
\text { Day of cycle }\end{array}$ & $\begin{array}{r}153 \\
15\end{array}$ & $\begin{array}{r}166 \\
12\end{array}$ & $\begin{array}{r}389 \\
24\end{array}$ & $\begin{array}{r}267 \\
22\end{array}$ & $\begin{array}{r}197 \\
20\end{array}$ & $\begin{array}{r}207 \\
10\end{array}$ & $\begin{array}{r}253 \\
15\end{array}$ & $\begin{array}{r}371 \\
17\end{array}$ & $\begin{array}{r}305 \\
11\end{array}$ & $\begin{array}{r}295 \\
16\end{array}$ & $\begin{array}{r}416 \\
22\end{array}$ & $\begin{array}{r}274 \\
16\end{array}$ & $\begin{array}{r}430 \\
16\end{array}$ \\
\hline $\begin{array}{l}\text { Serum LH peak } \\
(\mu \mathrm{g} \text { equiv. LER }\end{array}$ & & & & & & & & & & & & & \\
\hline $907 / 1)$ & 42 & $8 \cdot 4$ & 55 & - & 28 & $19 \cdot 8$ & 14.8 & 18 & 27 & $6 \cdot 0$ & $6 \cdot 6$ & 13 & 25 \\
\hline Day of cycle & 13 & 13 & 22 & - & 19 & 10 & 15 & 17 & 11 & 15 & 19 & 16 & 17 \\
\hline $\begin{array}{l}\text { Urinary LH peak } \\
\text { (i.u. 2nd IRP-HMG/ }\end{array}$ & & & & & & & & & & & & & \\
\hline $24 \mathrm{~h})$ & 89 & 73 & 120 & 71 & 80 & 72 & 150 & 100 & 55 & 68 & 88 & 170 & 110 \\
\hline Day of cycle & 14 & 15 & 24 & 20 & 20 & 10 & 16 & 18 & 11 & 19 & 22 & 16 & 17 \\
\hline $\begin{array}{l}\text { Urinary pregnanediol } \\
\text { peak }(\mu \mathrm{mol} / 24 \mathrm{~h})\end{array}$ & $14 \cdot 8$ & $17 \cdot 4$ & $18 \cdot 8$ & $<5^{*}$ & $15 \cdot 2$ & 7.6 & $14 \cdot 3$ & $7 \cdot 3$ & $29 \cdot 2$ & $8 \cdot 3$ & 14.8 & $14 \cdot 5$ & $8 \cdot 3$ \\
\hline Day of cycle & 22 & 24 & 29 & - & 30 & 18 & 22 & 24 & 20 & 24 & 28 & 24 & 26 \\
\hline
\end{tabular}

* In all samples.

peroxidase, is an effective bactericidal agent and indeed may also have spermicidal properties. If the levels of peroxidase were elevated at ovulation, then it could explain the reported reduced bactericidal action. Our results do not support this possibility.

Lyttle \& Jellinck (1972) presented evidence of a rat uterine peroxidase which is capable of accepting oestradiol as a substrate. They suggested that this peroxidase activity might be an adaptive response of the uterus to local increases in oestrogen levels, enabling it to limit the duration of effect of oestrogens on this target organ by inactivating them. It seemed possible that the present results in human cervical mucus might reflect the mid-cycle oestrogen peak. Although peroxidase activity in general was greater when the serial urinary oestrogen levels were also higher, the viscosity and amounts of mucus varied greatly on a day-to-day basis, in spite of the accuracy of the assay, which is much more sensitive than the assays described by Linford (1974) and Blain et al. (1975).

The difference between our results and those reported for cattle may simply reflect a species difference, because the decrease in cervical mucous peroxidase at oestrus for cattle was contrary to the result predicted from studies in other animals (Linford, 1974). Another possible cause of this discrepancy might be related to the sampling'technique. If the origin of the peroxidase is intracellular, then it may be that surface cells are scraped off by a finger-stall but are left relatively intact by our more gentle sampling procedure. This possibility is difficult to quantify but should be kept in mind during any future investigations.

We conclude from the results of this study that peroxidase activity does not necessarily reflect changing oestrogen activity in women and it cannot therefore be regarded as a reliable and independent index of ovulation in women in clinical practice, despite its use in veterinary science.

We thank I.C.I. (Dr A. Rushton, Pharmaceutical Division) and the M.R.C. for financial assistance and Miss L. Grubb, Miss K. Jones and Mrs A. E. Jones for technical assistance. 1.L. and J.S.S. thank the Manchester Area Health Authority for financial support.

\section{References}

Birnberg, C.H., Kurzrok, R. \& Laufer, A. (1958) A simple test for determining ovulation time. J. Am. Med. Ass. 166, 1174-1175.
Blain, J.A., Heald, P.J., Mack, A.E. \& Shaw, C.E. (1975) Peroxidase in human cervical mucus during the menstrual cycle. Contraception 11, 677-680. 
Brown, J.B., Macleod, S.C., Macnaughtan, C., SmTth, M.A. \& SMYTH, B. (1968) A rapid method for estimating oestrogens in urine using a semi-automatic extractor. J. Endocr. 42, 5-15.

ChILdS, R.E. \& BARDSLeY, W.G. (1975) The steady-state kinetics of horseradish peroxidase using ABTS as chromogen. Biochem. J. 145, 93-103.

Enhorning, G., Huldt, L. \& Melen, B. (1970) Ability of cervical mucus to act as a barrier against bacteria. Am.J. Obstet. Gynec. 108, 532-537.

GreenwOOD, F.C., HunTeR, W.M. \& GLOVer, J.S. (1963) The preparation of ${ }^{131}$ I-labelled Human Growth Hormone of high specific radioactivity. Biochem. J. 89, 114-123.

HARTREE, E.F. (1972) Determination of protein: a modification of the Lowry method that gives a linear photometric response. Analyt. Biochem. 48, 422-427.

LINFORD, E. (1974) Cervical mucus: an agent or barrier to conception? J. Reprod. Fert. 37, 239-250.

LyTtle, C.R. \& JellinCK, P.H. (1972) Metabolism of $\left[4-{ }^{14} \mathrm{C}\right]$ oestradiol by oestrogen-induced uterine peroxidase Biochem. J. 127, 481-487.

MidgleY, A.R., Jr (1966) Radioimmunoassy: a method for human chorionic gonadotrophin and human luteinizing hormone. Endocrinology, 79, 10-18.

Shindler, J.S., Childs, R.E. \& BARdsley, W.G. (1976) Peroxidase from human cervical mucus: the isolation and characterisation. Eur. J. Biochem. 65, 325331.

Received 28 February 1977 